\title{
Winter fungicide sprays impact the dynamics of vineyard Botrytis populations
}

\author{
P.R. Johnston, D. Park, W.P. Wilkie and A.F.R. Williams \\ Landcare Research, Private Bag 92170, Auckland, New Zealand \\ Corresponding author: johnstonp@landcareresearch.co.nz
}

Botrytis populations in vineyards often show seasonal differences. Early season populations tend to be less pathogenic than those at harvest. This change probably reflects differences in competitive ability in winter versus summer conditions. Such a seasonal pattern was observed in a Waipara vineyard from 2008 to 2012. The population at flowering was dominated by a Botrytis cinerea low pathogenicity haplotype; the population at harvest was dominated by a high pathogenicity haplotype. Since the 2013/2014 season, there has been a sudden change in this dynamic, with the high pathogenicity haplotype now dominant at both flowering and harvest. This change in the seasonal dynamic was confirmed using microsatellite analysis. A possible explanation for the change in behaviour of the Botrytis populations was a change in management practice, with the addition over the past 2-3 seasons of a winter GelSeal spray for control of vascular pathogens. GelSeal is a trizole fungicide effective against Botrytis. The change to the vineyard spray programme may have disrupted the competitive advantage the low-pathogenicity population previously enjoyed over winter. The possible impact of this change on levels of disease will be discussed in relation to similar seasonal changes in European grape powdery mildew populations, where there is a strong relationship between early season populations and disease at harvest.

\section{Where do spores go? Rain-splash patterns using surrogate dye.}

\author{
R.E. Campbell and M. Walter \\ Plant \& Food Research, Old Mill Rd, RD3, Motueka 7198, New Zealand \\ Corresponding author: Rebecca.campbell@plantandfood.co.nz
}

Microorganisms are incredibly difficult to trap, identify and enumerate efficiently and quickly. This makes it difficult to study incursions of new pathogens and the spread of existing ones effectively. Finding efficient ways of overcoming these difficulties is essential to guide monitoring protocols, control or mitigate spread, or find potential areas for eradication after incursions. We investigated the use of a fluorescent dye, PTSA (1,3,6,8-pyrenetetrasulfonic acid), to explore patterns of rain-splash dispersal of Neonectria ditissima spores. Spores mixed with PTSA dye were released in pear and apple trees within orchards and in an artificial setting using a marquee. Spores and dye were released from a central point source $2.5 \mathrm{~m}$ above ground and recaptured in a number of rain traps at ground level and within the tree canopy. It was often very difficult to detect low numbers of recaptured spores, with zero counts found at any distance from the release point. Data points were highly variable, as expected given the range of field conditions, but a clear relationship between dye and spores caught in rain traps under various scenarios was obtained. These results show the merit of PTSA tracer dye as a tool to quantify potential dispersal patterns of microorganisms in an actual landscape of interest with various rainfall scenarios. 